(2) Open Access Full Text Article

\title{
A study of silver (I) perchlorate as an effective promoter for chemical glycosylation with thioimidates and thioglycosides
}

This article was published in the following Dove Press journal:

Reports in Organic Chemistry

20 February 2014

Number of times this article has been viewed

\author{
Scott J Hasty \\ Sneha C Ranade \\ Alexei $\vee$ Demchenko \\ Department of Chemistry and \\ Biochemistry, University of \\ Missouri-St Louis, St Louis, \\ Missouri, USA
}

Correspondence: Alexei V Demchenko University of Missouri-St Louis,

One University Boulevard, 315 Benton Hall (MC27), St Louis, MO 63I2I, USA

Tel +I 3145167995

$\mathrm{Fax}+\mathrm{I} 3145165342$

Email demchenkoa@umsl.edu
Abstract: It has been previously acknowledged that perchlorate salts may be beneficial for the formation of 1,2-cis glycosides. Here, we demonstrate the effectiveness of silver (I) perchlorate as a powerful promoter of glycosyl thioimidate activation. Improved 1,2-cis selectivity was obtained, compared against that obtained with other silver (I) salts, including commonly-used triflate. The use of a combination of silver (I) perchlorate and methyl sulfenyl bromide to activate thioglycosides was also investigated. The cooperative use of these activation protocols was applied to a one-pot, two-step sequential activation, using thioimidate and thioglycoside building blocks.

Keywords: carbohydrates, glycosylation, perchlorate, methodology, promoter

\section{Introduction}

Aspiration to understand the involvement of carbohydrates in practically all lifesustaining, and many life-threatening biological processes has been the major driving force in the glycosciences. ${ }^{1}$ A key to understanding the biological roles that carbohydrates play is to have straightforward access to synthetic oligosaccharides and their conjugates. Chemical synthesis of complex oligosaccharides, particularly those containing challenging 1,2-cis glycosidic linkages, ${ }^{2-4}$ has long been considered a major challenge. Various factors, such as protecting and leaving groups, promoter/ activator, solvent, temperature, etc, may have a significant impact on the course and the outcome of the glycosylation reaction..$^{5}$ Nevertheless, there are still significant gaps in our knowledge of the glycosylation reaction and its mechanism. ${ }^{6-9}$ For instance, the effect of the counter-anion remains unclear. Since a vast majority of promoters rely on the use of triflates (trifluoromethanesulfonates) (Tf), ${ }^{10}$ the function of triflate as the counter-anion (or as the covalently-bound reaction intermediate) during the glycosylation reaction is established, and has been extensively studied. ${ }^{11,12}$ Another well-studied phenomenon is halide anion-mediated glycosylation, wherein the involvement of bromide ${ }^{13}$ and iodide ${ }^{14,15}$ anions has been related to high 1,2-cis selectivity. The effect of other counter-ions is largely unknown, although it has been noticed that high 1,2-cis stereoselectivity can be achieved using tritylium perchlorate ${ }^{16-18}$ or iodonium(di- $\gamma$-collidine)perchlorate ${ }^{19,20}$ as promoters, or lithium perchlorate ${ }^{21-25}$ as an additive. To the best of our knowledge, no systematic studies of perchlorate salts as promoters of glycosylation have yet been reported. ${ }^{26}$ Expanding upon previous use of $\mathrm{AgClO}_{4}$ as the promoter ${ }^{27}$ or as an additive in glycosylations, ${ }^{24,28}$ we here report our preliminary study of this promoter for the activation of various thioimidoyl and thioglycosyl donors. submit your manuscript | www.dovepress.com

Dovepress

http://dx.doi.org/10.2147/ROC.S32147
Reports in Organic Chemistry 2014:4 1-10

(c) (i) (5) 2014 Hasty et al. This work is published by Dove Medical Press Limited, and licensed under Creative Commons Attribution - Non Commercial (unported, v3.0) License. The full terms of the License are available at http://creativecommons.org/licenses/by-nc/3.0/. Non-commercial uses of the work are permitted without any further Dove Medical Press Limited, provided the work is properly attributed. Permissions beyond the scope of the License are administered by Dove Medical Press Limited. Information on how to request permission may be found at: http://www.dovepress.com/permissions.php 


\section{Experimental General}

Column chromatography was performed on EM Science Silica Gel 60 (70-230 mesh) (Cambridge Scientific, Watertown, MA, USA); reactions were monitored by thin layer chromatography (TLC) on EM Science Kieselgel 60 F254. Compounds were detected by examination under ultraviolet light, and by charring with $10 \%$ sulfuric acid in methanol. Solvents were removed under reduced pressure at $<40^{\circ} \mathrm{C} . \mathrm{CH}_{2} \mathrm{Cl}_{2}$ and $\mathrm{ClCH}_{2} \mathrm{CH}_{2} \mathrm{Cl}$ were distilled from $\mathrm{CaH}_{2}$ immediately prior to usage. Acetonitrile was dried by refluxing with $\mathrm{CaH}_{2}$, then distilled and stored over molecular sieves ( $3 \AA$ ). Tetrahydrofuran (THF) was refluxed for 2 hours, then distilled over sodium, using benzophenone as an indicator under argon, directly before use. Acetone was dried by refluxing with $\mathrm{K}_{2} \mathrm{CO}_{3}$, then distilled and stored over molecular sieves ( $3 \AA$ ). The molecular sieves used for reactions $(3 \AA)$ were crushed and activated in vacuo at $390^{\circ} \mathrm{C}$ for 8 hours, in the first instance, and then for 2-3 hours at $390^{\circ} \mathrm{C}$, directly prior to application. $\mathrm{AgClO}_{4}$ (Sigma-Aldrich, St Louis, MO, USA) was used as is. Warning: avoid or control reaction with peroxides. All transition metal perchlorates should be considered as potentially explosive; avoid storing with fluorobenzenes, nitromethane, acetylene, peroxides, strong mineral acids, metals, and metal hydrides; refer to the manufacturer's specifications for full recommendations regarding hazards, handling, and storage. $\mathrm{AgPF}_{6}$ (Acros Organics, Thermo Fisher Scientific, Bridgewater, NJ, USA) and $\mathrm{AgBF}_{4}$ (Acros Organics) were used as is. Silver (I) triflate (AgOTf) (Acros Organics) was co-evaporated with toluene $(3 \times 10 \mathrm{~mL})$ and dried in vacuo for $2-3$ hours directly prior to application. Optical rotations were measured using a Jasco P-1020 polarimeter (Jasco Inc, Easton, MD, USA). Proton nuclear magnetic resonance ( $\left.{ }^{1} \mathrm{H}-\mathrm{NMR}\right)$ spectra were recorded in $\mathrm{CDCl}_{3}$ at $300 \mathrm{MHz}$ and Carbon-13 nuclear magnetic resonance $\left({ }^{13} \mathrm{C}\right.$-NMR) spectra were recorded in $\mathrm{CDCl}_{3}$ at $75 \mathrm{MHz}$ (Avance, Bruker Corp, Billerica, MA, USA), unless otherwise noted. High resolution mass spectroscopy (HRMS) determinations were made using a JMS-700 MStation ${ }^{\mathrm{TM}}$ mass spectrometer (JEOL, Tokyo, Japan).

\section{Synthesis of glycosyl donors}

Phenyl 3,4,6-tri-O-benzoyl-2-O-benzyl-Ithio- $\beta$-D-glucopyranoside (4)

A $5.0 \mathrm{~mL}$ solution of $\mathrm{NaSPh}$ in THF, freshly prepared from $60 \% \mathrm{NaH}(2.36 \mathrm{mmol})$ and $\mathrm{HSPh}(2.36 \mathrm{mmol})$, and 15-crown-5 (0.16 mL, $0.8 \mathrm{mmol})$ were added to a stirring solution of 3,4,6-tri-O-benzoyl-2-O-benzyl- $\alpha$-D-glucopyranosyl $\operatorname{bromide}^{35}(0.85 \mathrm{~g}, 1.6 \mathrm{mmol})$ in dry THF $(5.0 \mathrm{~mL})$, then the reaction mixture was stirred under argon for 2.5 hours at room temperature. Upon completion, the reaction mixture was diluted with $\mathrm{CH}_{2} \mathrm{Cl}_{2}(\sim 100 \mathrm{~mL})$, washed first with water $(10 \mathrm{~mL})$, then with saturated aqueous solution (sat aq) of $\mathrm{NaHCO}_{3}(10 \mathrm{~mL})$, then with water $(3 \times 10 \mathrm{~mL})$. The organic phase was then separated, dried over $\mathrm{Na}_{2} \mathrm{SO}_{4}$, and concentrated in vacuo. The residue was purified by column chromatography on silica gel (ethyl acetate-hexane gradient elution) to afford the title compound in $73 \%$ yield $(0.65 \mathrm{~g})$ as a white foam. Analytical data for 4: $\mathrm{R}_{f}=0.48$ (ethyl acetate/hexanes: $3 / 7$, $\mathrm{v} / \mathrm{v}) ;[\alpha]_{\mathrm{D}}{ }^{22} 10.4\left(\mathrm{c}=1.0, \mathrm{CHCl}_{3}\right) ;{ }^{1} \mathrm{H}-\mathrm{NMR}: \delta, 3.78(\mathrm{dd}, 1 \mathrm{H}$, $\left.J_{2,3}=9.4 \mathrm{~Hz}, \mathrm{H}-2\right), 4.07\left(\mathrm{~m}, 1 \mathrm{H}, J_{5,6 \mathrm{a}}=6.1, J_{5,6 \mathrm{~b}}=2.8 \mathrm{~Hz}, \mathrm{H}-5\right)$, 4.45 (dd, $\left.1 \mathrm{H}, J_{6 \mathrm{a}, 6 \mathrm{~b}}=12.2 \mathrm{~Hz}, \mathrm{H}-6 \mathrm{a}\right), 4.61$ (dd, $\left.1 \mathrm{H}, \mathrm{H}-6 \mathrm{~b}\right), 4.72$ (dd, $\left.2 \mathrm{H},{ }^{2} J=10.7 \mathrm{~Hz}, \mathrm{CH}_{2} \mathrm{Ph}\right), 4.91\left(\mathrm{~d}, 1 \mathrm{H}, J_{1,2}=9.7 \mathrm{~Hz}, \mathrm{H}-1\right.$ ), $5.50\left(\mathrm{dd}, 1 \mathrm{H}, J_{4,5}=9.8 \mathrm{~Hz}, \mathrm{H}-4\right), 5.78\left(\mathrm{dd}, 1 \mathrm{H}, J_{3,4}=9.3 \mathrm{~Hz}, \mathrm{H}-3\right)$, 7.02-8.12 (m, 25H, aromatic) ppm; ${ }^{13} \mathrm{C}-\mathrm{NMR}: \delta, 63.5,69.6$, $75.3,75.9,76.1,78.5,87.8,127.9,128.0,128.1,128.4(\times 3)$, $128.5(\times 7), 128.9,129.1(\times 2), 129.4,129.8(\times 2), 129.9(\times 3)$, $130.0(\times 2), 130.3,132.5,133.0,133.3,133.6,137.2,165.6$, 165.7, 166.2 ppm; HR-FAB MS [M+Na $]^{+}$calculated (calcd) for $\mathrm{C}_{40} \mathrm{H}_{34} \mathrm{O}_{8} \mathrm{SNa}^{+}$697.1872, found 697.1868.

\section{2-benzimidazolyl 3,4,6-tri-O-benzoyl-2- \\ O-benzyl- I-thio- $\beta$-D-glucopyranoside (7)}

Potassium 2-benzimidazolethione ${ }^{36}$ (KSBiz) (0.66 g; $3.5 \mathrm{mmol})$ and 18 -crown- $6(0.12 \mathrm{mg} ; 0.46 \mathrm{mmol})$ were added to a stirring solution of 3,4,6-tri-O-benzoyl-2-O-benzyl- $\alpha$-Dglucopyranosyl bromide $(1.25 \mathrm{~g} ; 2.3 \mathrm{mmol})$ in dry acetone $(10 \mathrm{~mL})$, then the reaction mixture was stirred under argon for 4 hours at room temperature. Upon completion, the solid was filtered off and rinsed successively with $\mathrm{CH}_{2} \mathrm{Cl}_{2}$. The combined filtrate $(\sim 250 \mathrm{~mL})$ was washed first with water $(20 \mathrm{~mL})$, then with sat aq $\mathrm{NaHCO}_{3}(20 \mathrm{~mL})$, and then with water $(3 \times$ $20 \mathrm{~mL}$ ). The organic phase was separated, dried over $\mathrm{Na}_{2} \mathrm{SO}_{4}$, and concentrated in vacuo. The residue was purified by column chromatography on silica gel (ethyl acetate-toluene gradient elution) to afford the title compound in $62 \%$ yield $(0.82 \mathrm{~g})$ as a white foam. Analytical data for $7: \mathrm{R}_{f}=0.051$ (ethyl acetate/ hexanes: $1 / 1, \mathrm{v} / \mathrm{v}) ;[\alpha]_{\mathrm{D}}{ }^{22}-130.9\left(\mathrm{c}=1.0, \mathrm{CHCl}_{3}\right) ;{ }^{1} \mathrm{H}-\mathrm{NMR}$ : $\delta, 3.75\left(\mathrm{~d}, 1 \mathrm{H}, J_{2,3}=9.3 \mathrm{~Hz}, \mathrm{H}-2\right), 4.18\left(\mathrm{~m}, 1 \mathrm{H}, J_{5,6 \mathrm{a}}=6.6\right.$, $\left.J_{5,6 \mathrm{~b}}=2.2 \mathrm{~Hz}, \mathrm{H}-5\right), 4.62$ (dd, 1H, $\left.J_{6 \mathrm{a}, 6 \mathrm{~b}}=12.5 \mathrm{~Hz}, \mathrm{H}-6 \mathrm{a}\right), 4.77$ (dd, 1H, H-6b), 4.85 (dd, 2H, ${ }^{2}=10.8 \mathrm{~Hz}, \mathrm{CH}_{2} \mathrm{Ph}$ ), 5.05 (d, $\left.1 \mathrm{H}, J_{1,2}=9.5 \mathrm{~Hz}, \mathrm{H}-1\right), 5.53$ (dd, $\left.1 \mathrm{H}, J_{4,5}=9.8 \mathrm{~Hz}, \mathrm{H}-4\right), 5.83$ (dd, $\left.1 \mathrm{H}, J_{3,4}=9.3 \mathrm{~Hz}, \mathrm{H}-3\right), 7.06-8.18(\mathrm{~m}, 24 \mathrm{H}$, aromatic), 10.64 (br. s, $1 \mathrm{H}, \mathrm{NH}) \mathrm{ppm} ;{ }^{13} \mathrm{C}-\mathrm{NMR}: \delta, 62.9,68.9,75.3$, $75.5,78.5,84.5,123.1,128.1,128.4(\times 4), 128.5(\times 3), 128.7$ $(\times 2), 128.8(\times 4), 128.9(\times 2), 129.2,129.6,129.9(\times 3), 130.0$ 
(×3), $130.2(\times 3), 133.4,133.8,140.0,143.8,165.4,165.7$, 167.4 ppm; HR-FAB MS [M+Na] $]^{+}$calcd for $\mathrm{C}_{41} \mathrm{H}_{34} \mathrm{~N}_{2} \mathrm{O}_{8} \mathrm{SNa}^{+}$ 737.1934, found 737.1930.

\section{2-O-benzyl-3,4,6-tri-O-benzoyl- I-thio- $\beta$-D-} glucopyranosyl O-methyl phenylcarbamothioate (8) O-Methyl phenylcarbamothioate (HSNea) (0.22 g. $1.29 \mathrm{mmol})$ and $\mathrm{KOH}(0.048$ g. $0.85 \mathrm{mmol})$ were added to a stirring solution of 3,4,6-tri-O-benzoyl-2-O-benzyl- $\alpha$-Dglucopyranosyl bromide $(0.46$ g. $0.85 \mathrm{mmol})$ in dry acetone $(6.0 \mathrm{~mL})$, and the reaction mixture was stirred under argon for 2.5 hours at room temperature. Upon completion, the solid was filtered off and rinsed successively with $\mathrm{CH}_{2} \mathrm{Cl}_{2}$. The combined filtrate $(\sim 100 \mathrm{~mL})$ was washed with water $(10 \mathrm{~mL})$, then with sat aq $\mathrm{NaHCO}_{3}(10 \mathrm{~mL})$, and then with water $(3 \times 10 \mathrm{~mL})$. The organic phase was separated, dried over $\mathrm{Na}_{2} \mathrm{SO}_{4}$, and concentrated in vacuo. The residue was purified by column chromatography on silica gel (ethyl acetate-hexane gradient elution) to afford the title compound in $42 \%$ yield $(0.22 \mathrm{~g})$ as a white foam. Analytical data for 8 : $\mathrm{R}_{f}=0.42$ (ethyl acetate/hexanes: $\left.3 / 7, \mathrm{v} / \mathrm{v}\right) ;[\alpha]_{\mathrm{D}}^{22}-14.3$ (c=1.0, $\mathrm{CHCl}_{3}$ ); ${ }^{1} \mathrm{H}-\mathrm{NMR}: \delta, 3.69$ (dd, $\left.1 \mathrm{H}, J_{2,3}=9.1 \mathrm{~Hz}, \mathrm{H}-2\right), 3.90$ $\left(\mathrm{s}, 3 \mathrm{H}, \mathrm{OCH}_{3}\right), 4.13\left(\mathrm{~m}, 1 \mathrm{H}, J_{5,6 \mathrm{a}}=5.9, J_{5,6 \mathrm{~b}}=2.9 \mathrm{~Hz}, \mathrm{H}-5\right), 4.44$ (dd, $\left.1 \mathrm{H}, J_{6 \mathrm{a}, 6 \mathrm{~b}}=12.2 \mathrm{~Hz}, \mathrm{H}-6 \mathrm{a}\right), 4.54\left(\mathrm{dd}, 2 \mathrm{H},{ }^{2} J=10.6 \mathrm{~Hz}\right.$, $\mathrm{CH}_{2} \mathrm{Ph}$ ), 4.58 (dd, $\left.1 \mathrm{H}, \mathrm{H}-6 \mathrm{~b}\right), 5.41$ (d, $1 \mathrm{H}, J_{1,2}=10.0 \mathrm{~Hz}, \mathrm{H}-1$ ), 5.47 (dd, $\left.1 \mathrm{H}, J_{4,5}=9.8 \mathrm{~Hz}, \mathrm{H}-4\right), 5.77$ (dd, $1 \mathrm{H}, J_{3,4}=9.4 \mathrm{~Hz}$, $\mathrm{H}-3$ ), 6.79-8.07 (m, 25H, aromatic) ppm; ${ }^{13} \mathrm{C}-\mathrm{NMR}: \delta$, 56.6, 63.5, 69.7, 75.4, 76.0, 76.3, 83.1, $121.7(\times 2), 124.12$, $128.1,128.4(\times 8), 128.5(\times 3), 128.9,129.2(\times 2), 129.3$, $129.8(\times 4), 129.9(\times 2), 133.3,133.4,133.5,136.8,146.8$, $155.2,165.5,165.7,166.2$ ppm; HR-FAB MS[M+Na ${ }^{+}$ calcd for $\mathrm{C}_{42} \mathrm{H}_{37} \mathrm{NO}_{9} \mathrm{SNa}^{+}$754.2081, found 754.2089.

\section{2-benzoxazolyl 3,4,6-tri-O-acetyl-2-azido-}

2-deoxy- I-thio- $\beta$-D-glucopyranoside (25)

Potassium 2-mercaptobenzoxazole ${ }^{29}$ (KSBox) (0.600 g, $3.17 \mathrm{mmol})$ and 18 -crown-6 $(0.67 \mathrm{~g}, 0.25 \mathrm{mmol})$ were added to a stirring solution of 3,4,6-tri-O-acetyl-2-azido-2-deoxy- $\alpha$-Dglucopyranosyl bromide ${ }^{30}(0.50 \mathrm{~g}, 1.27 \mathrm{mmol})$ in dry acetone $(10 \mathrm{~mL})$, then the reaction mixture was stirred under argon for 2.5 hours at room temperature. Upon completion, the solid was filtered off and rinsed successively with $\mathrm{CH}_{2} \mathrm{Cl}_{2}$. The combined filtrate $(\sim 250 \mathrm{~mL})$ was washed with water $(20 \mathrm{~mL})$, then with sat aq $\mathrm{NaHCO}_{3}(20 \mathrm{~mL})$, and then with water $(3 \times 20 \mathrm{~mL})$. The organic phase was separated, dried over $\mathrm{Na}_{2} \mathrm{SO}_{4}$, and concentrated in vacuo. The residue was purified by column chromatography on silica gel (ethyl acetate-hexane gradient elution) to afford the title compound in $37 \%$ yield $(0.218 \mathrm{~g})$ as an off-white foam. Analytical data for $25: \mathrm{R}_{f}=0.49$ (ethyl acetate/hexanes: $1 / 1, \mathrm{v} / \mathrm{v}) ;[\alpha]_{\mathrm{D}}{ }^{22} 9.1\left(\mathrm{c}=1.0, \mathrm{CHCl}_{3}\right) ;{ }^{1} \mathrm{H}-\mathrm{NMR}: \delta, 1.99,2.05,2.13$ $\left(3 \mathrm{~s}, 9 \mathrm{H}, 3 \times \mathrm{CH}_{3}\right), 3.91\left(\mathrm{~m}, 1 \mathrm{H}, J_{5,6 \mathrm{a}}=2.2, J_{5,6 \mathrm{~b}}=4.7 \mathrm{~Hz}, \mathrm{H}-5\right) 3.94$ (dd, $\left.1 \mathrm{H}, J_{2,3}=9.5 \mathrm{~Hz}, \mathrm{H}-2\right), 4.12$ (dd, $1 \mathrm{H}, J_{6 a, 6 \mathrm{~b}}=12.5 \mathrm{~Hz}, \mathrm{H}-6 \mathrm{a}$ ), 4.27 (dd, 1H, H-6b), 5.12 (dd, 1H, $J_{4,5}=9.5 \mathrm{~Hz}, \mathrm{H}-4$ ), 5.25 (dd, $\left.1 \mathrm{H}, J_{3,4}=9.5 \mathrm{~Hz}, \mathrm{H}-3\right), 5.42\left(\mathrm{~d}, 1 \mathrm{H}, J_{1,2}=10.5 \mathrm{~Hz}, \mathrm{H}-1\right), 7.27-7.68$ (m, 4H, aromatic) ppm; ${ }^{13} \mathrm{C}-\mathrm{NMR}: 20.7,20.8(\times 2), 61.8,63.1$, 70.0, 74.7, 76.6, 84.1, 110.4, 119.3, 124.8, 124.9, 141.7, 152.1, $160.1,169.8,170.0,170.7$ ppm; HR-FAB MS[M+H] ${ }^{+}$calcd for $\mathrm{C}_{19} \mathrm{H}_{21} \mathrm{~N}_{4} \mathrm{O}_{8} \mathrm{~S}^{+} 465.1080$, found 465.1072 .

\section{Typical procedure for glycosidation of thioimidates}

A mixture of glycosyl donor ( $0.033 \mathrm{mmol})$, glycosyl acceptor $(0.030 \mathrm{mmol})$, and freshly activated molecular sieves (3 A, $125 \mathrm{mg})$ in 1,2-dichloroethane $(1 \mathrm{~mL})$ was stirred under argon for 1 hour. Silver (I) salt $(0.068 \mathrm{mmol})$ was added, and the reaction mixture was monitored by TLC. Upon completion (Tables 1 and 2), the solid was filtered off and the filtrate was diluted with $\mathrm{CH}_{2} \mathrm{Cl}_{2}(15 \mathrm{~mL})$, washed with $1 \% \mathrm{NaOH}(5 \mathrm{~mL})$, then water $(3 \times 5 \mathrm{~mL})$. The organic layer was separated, dried with $\mathrm{Na}_{2} \mathrm{SO}_{4}$, and concentrated in vacuo. The residue was purified by column chromatography on silica gel (ethyl acetate-hexane gradient elution) to afford the corresponding oligosaccharide.

Table I Comparative study of $\mathrm{AgClO}_{4}$ versus other $\mathrm{Ag}$ (I) salts

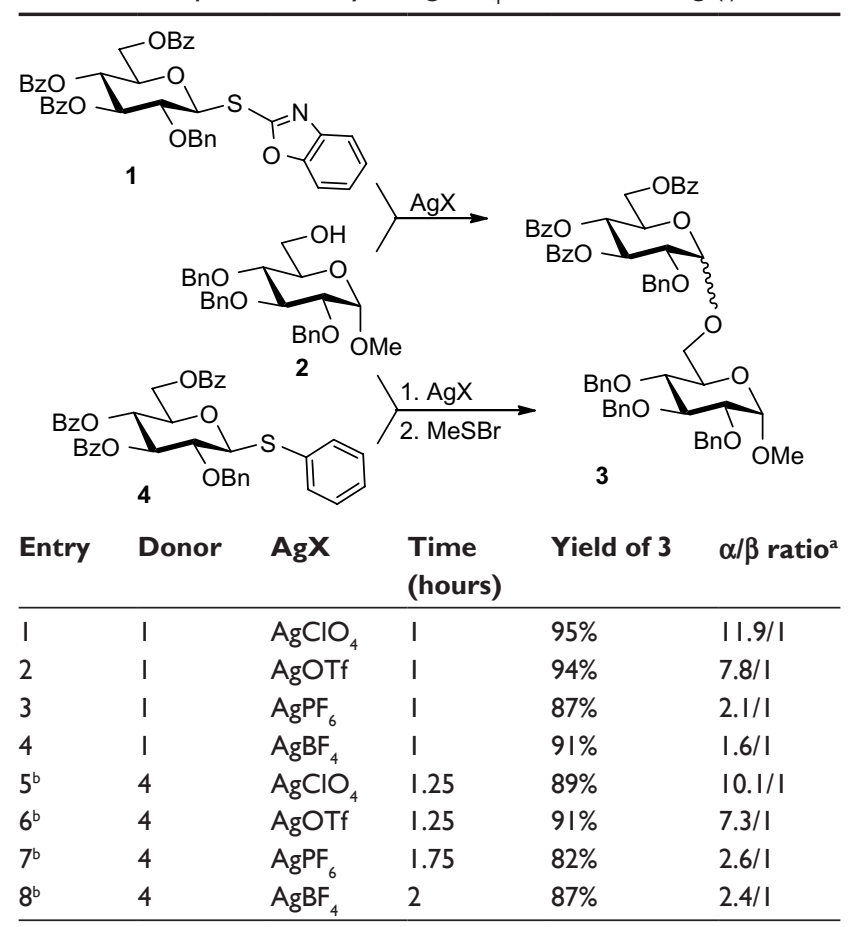

Notes: The anomeric ratios have been determined by comparing the integral intensities of the corresponding signals in proton nuclear magnetic resonance spectra; ${ }^{b}$ performed in the presence of $\mathrm{MeSBr}$.

Abbreviations: AgOTf, silver (I) triflate; $\mathrm{MeSBr}$, methyl sulfenyl bromide. 
Table 2 Investigation of $\mathrm{AgClO}_{4}$ as promoter of glycosylation with thioimidate and thioglycoside donors

Entry Donor

I

2

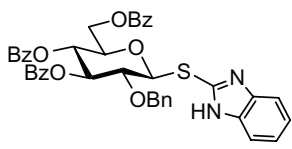

3

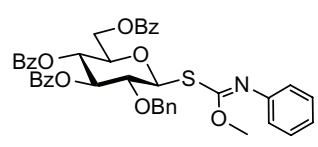

4

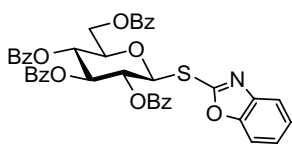

59

6

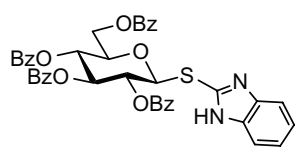

12

7

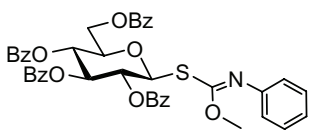

13

$8^{\mathrm{a}}$

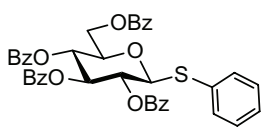

14

9

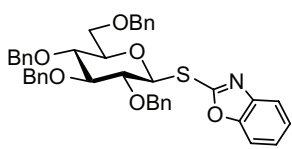

15

$10 \quad 15$

II

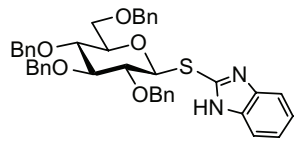

Acceptor

5

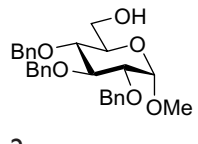

2

2

2

$30 \mathrm{~min}$

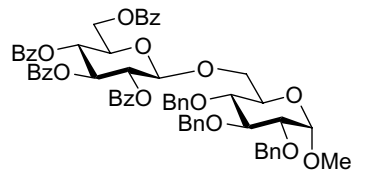

$30 \min$

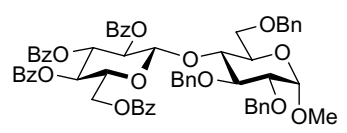

$45 \min \quad 10$

$45 \min \quad 10$

$20 \min \quad 10$

$15 \mathrm{~min}$

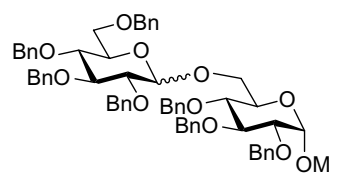

$15 \mathrm{~min}$

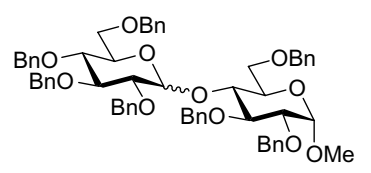

17

$15 \min \quad 16$
10

II

16

Yield

$\alpha / \beta$ ratio

$92 \%$

$>20 / 1$

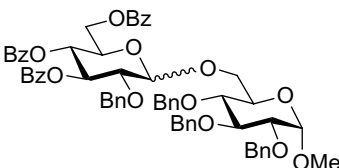

$93 \%$

$11.2 / 1$

$91 \% \quad \beta$ only

$94 \%$

$\beta$ only

$2 \%$

$\beta$ only

$89 \%$

18 
Table 2 (Continued)

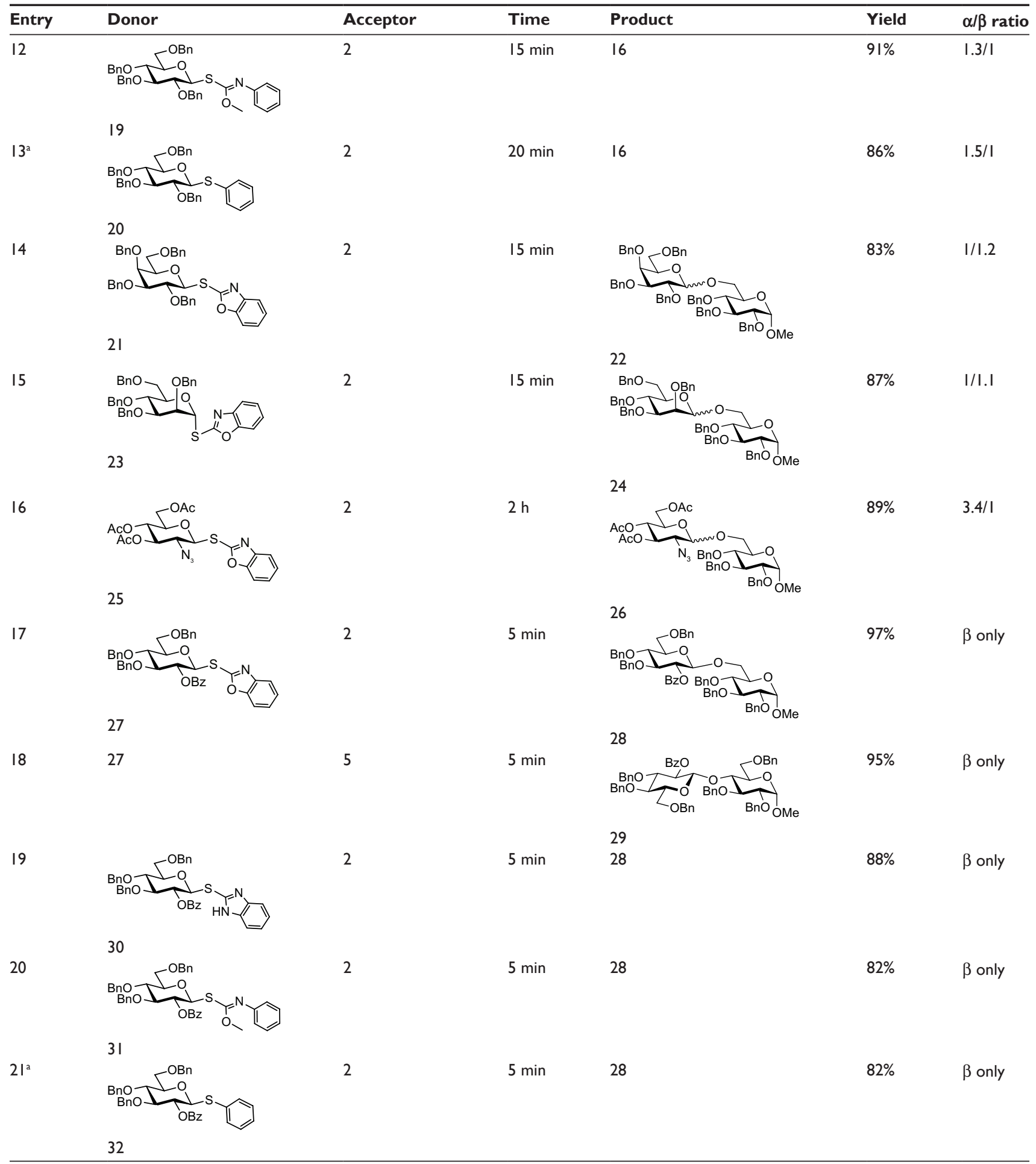

Note: aPerformed in the presence of $\mathrm{MeSBr}$.

Abbreviations: min, minute; h, hour; $\mathrm{MeSBr}$, methyl sulfenyl bromide.

\section{Typical procedure for glycosidation of thioglycosides}

A mixture of glycosyl donor ( $0.033 \mathrm{mmol})$, glycosyl acceptor $(0.030 \mathrm{mmol})$, and freshly activated molecular sieves (3 A, $125 \mathrm{mg})$ in 1,2-dichloroethane $(1 \mathrm{~mL})$ was stirred under argon for 1 hour. Silver (I) salt $(0.068 \mathrm{mmol})$ was added first, followed by freshly-prepared methyl sulfenyl bromide (MeSBr), ${ }^{31}$ and the reaction mixture was monitored using TLC. Upon completion (Tables 1 and 2), the solid was filtered off and the filtrate was diluted with $\mathrm{CH}_{2} \mathrm{Cl}_{2}(15 \mathrm{~mL})$, 
then washed with $1 \% \mathrm{NaOH}(5 \mathrm{~mL})$, then water $(3 \times 5 \mathrm{~mL})$. The organic layer was separated, dried with $\mathrm{Na}_{2} \mathrm{SO}_{4}$, and concentrated in vacuo. The residue was purified by column chromatography on silica gel (ethyl acetate-hexane gradient elution), to afford the corresponding oligosaccharide.

\section{Results and discussion}

Over the last decade, we have been interested in syntheses and applications of various glycosyl thioimidates as new, versatile building blocks for chemical glycosylation and expeditious oligosaccharide synthesis. ${ }^{32}$ S-Benzoxazolyl (SBox), ${ }^{33}$ S-thiazolinyl (STaz), ${ }^{34}$ O-methyl phenylcarbamothioate (SNea), ${ }^{35}$ and S-benzimidazolyl $(\mathrm{SBiz})^{36}$ are all commonly activated with AgOTf. This activation pathway often gives superior yields and stereoselectivity, compared against those achieved with other activators. However, AgOTf is very sensitive to moisture, and typically requires thorough conditioning prior to use. To address this, we introduced silver (I) tetrafluoroborate $\left(\mathrm{AgBF}_{4}\right)$ as a powerful activator for thioimidates. ${ }^{37}$ Nevertheless, the synthesis of 1,2-cis glycosides, in a majority of applications, using either promoter, provided only marginal stereoselectivity. In our preliminary evaluation of various silver (I) salts, we noticed that $\mathrm{AgClO}_{4}$ provides consistently superior 1,2-cis selectivity. This observation triggered our interest in a more detailed study of this promoter in its application to glycosylations with thioimidate and thioglycoside donors.

To pursue this aim, we obtained SBox donor $1,{ }^{38}$ which was subjected to a series of parallel glycosylations using various silver (I) salts (Table 1). Thus, the reaction of glycosyl donor 1 with primary glycosyl acceptor $2,{ }^{35}$ in the presence of $\mathrm{AgClO}_{4}$, afforded disaccharide $3^{39}$ in $95 \%$ yield, and very commendable stereoselectivity $(\alpha / \beta=11.9 / 1$; Entry 1). Very comparable outcomes, in terms of yields and reactivity rates, were detected in cases when AgOTf, silver hexafluorophosphate $\left(\mathrm{AgPF}_{6}\right)$, and $\mathrm{AgBF}_{4}$ were used as promoters of the glycosylation of acceptor 2 with SBox donor 1 (Entries 2-4). In all cases, disaccharide 3 was isolated in good yields (87\%-94\%), but with significantly reduced selectivity, in comparison to that recorded for $\mathrm{AgClO}_{4}$. The stereoselectivity recorded in these parallel experiments ranged from good $(\alpha / \beta=7.8 / 1$; Entry 2$)$, for AgOTf, to rather poor for $\operatorname{AgPF}_{6}(\alpha / \beta=2.1 / 1$; Entry 3$)$ and $\operatorname{AgBF}_{4}(\alpha / \beta=1.6 / 1$; Entry 4$)$. Since all other reaction conditions remained the same, and no significant changes in the reaction rate were observed (all reactions were completed within 1 hour), this differential stereoselectivity is arguably indicative of the effect of the counter-anion. The results surveyed clearly indicate that the perchlorate anion creates the most favorable environment for the formation of $\alpha$-linked disaccharide 3 .

In principle, one could envisage a variety of modes by which the counter-anion may be involved in (and possibly influence) the glycosylation reaction. Nevertheless, this key effect is often overlooked (apart from the effect of triflate, which has been thoroughly studied by Crich et al). ${ }^{11,40}$ As it was previously demonstrated for AgOTf, the activation of the SBox leaving group takes place via the anomeric sulfur. ${ }^{41}$ The resultant glycosyl cation may then be stabilized via the oxacarbenium cation (Figure 1A) with counter-anion (triflate - or $\mathrm{X}$, in a more general sense). In the case of nucleophilic counter-anions, such as triflate or perchlorate, but not tetrafluoroborate or pentafluorophosphate, formal covalent attachment of $\mathrm{X}$ is another possible intermediate (Figure 1B). If the neighboring substituent at C-2 is an acyl group, glycosylations may also proceed via an acyloxonium intermediate (Figure 1C). The subsequent glycosyl acceptor attack can be influenced by the steric and electronic properties of $\mathrm{X}$, particularly if the reaction proceeds via the intermediacy of either A or B. It should be noted that all reaction intermediates are quite unstable. Therefore, the exact mechanism of chemical glycosylation remains elusive. ${ }^{8,9}$

We were interested in investigating the effect of perchlorate anion on the glycosidation of thioglycosides, common donors for chemical glycosylation. ${ }^{42}$ Since a silver (I) salt alone fails to activate thioglycosides, its inclusion into the promoter system was explored. Herein, we chose to investigate the combination of MeSBr (introduced by Dasgupta and Garegg as a co-promoter of glycosylation) ${ }^{31}$ and $\mathrm{AgX}$. Another possibility would be to use $\mathrm{N}$-iodosuccinimide (NIS)/AgX combination, because NIS/AgOTf is a rather common promoter system for thioglycoside activation. ${ }^{42}$ To carry out this reaction, $\mathrm{MeSBr}$ was added to a mixture

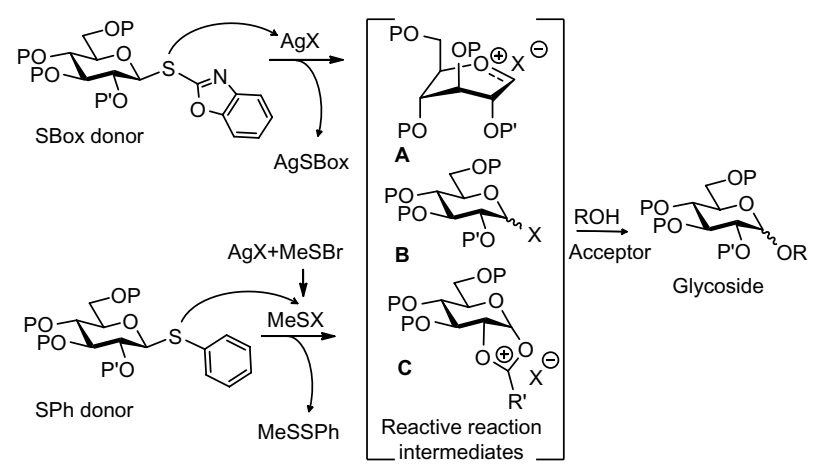

Figure I Schematic representation of the reaction mechanism. Abbreviation: Box, S-benzoxazolyl. 
containing thioglycoside (SPh) donor 4, glycosyl acceptor 2, and $\operatorname{AgX}$ (refer to the experimental section for further details). The formation of insoluble yellow precipitate $(\mathrm{AgBr})$ could be detected momentarily. Apparently, MeSX is also formed at this time (Figure 1), which then undergoes nucleophilic attack by the anomeric sulfur, forming the glycosyl sulfonium intermediate. According to the generally accepted activation mechanism, ${ }^{6}$ the leaving group then departs as a disulfide (PhSSMe) leading to the activated intermediates (Figure 1A-C) or a combination thereof, depending on the original structure and other factors (vide supra).

Following this pathway, the activation of SPh donor 4 with $\mathrm{MeSBr} / \mathrm{AgClO}_{4}$ for reaction with primary acceptor 2 afforded disaccharide 3 in $89 \%$ yield with very respectable stereoselectivity $(\alpha / \beta=10.1 / 1$; Entry 5$)$ (Table 1$)$. Similar outcomes, in terms of yields and reactivity, were detected in cases wherein AgOTf, $\mathrm{AgPF}_{6}$, and $\mathrm{AgBF}_{4}$ were used as promoters for glycosylation of acceptor 2 with $\mathrm{SPh}$ donor 4 (Entries 6-8). Thus, disaccharide 3 was isolated in good yields ( $82 \%-91 \%)$, but with significantly reduced selectivity $(\alpha / \beta=2.4-7.3 / 1)$. Since the difference in the reaction rates between different promoters was insignificant, we believe that it is the effect of the counter-anion that influences the stereoselectivity of glycosylations. Once again, the results indicate that perchlorate is the most favorable counter-ion for the formation of $\alpha$-glucoside 3 . These results were deemed both practical and intriguing. Hence, we decided to undergo subsequent comprehensive investigation of this promising promoter.

To determine the efficacy of $\mathrm{AgClO}_{4}$ in the context of other classes of glycosidic linkages and substrates, we examined a wider range of glycosyl donors. The key findings of this study are summarized in Table 2. As a direct continuation of our preliminary work, we set up a series of experiments with 2-O-benzyl-3,4,6-tri-O-benzoyl-protected (superdisarmed) ${ }^{43}$ thioimidoyl donors. First, we performed glycosylation of the secondary glycosyl acceptor $5^{35}$ with SBox donor 1 . This coupling produced disaccharide $6^{44}$ in $92 \%$ yield, and an impressive stereoselectivity $(\alpha / \beta=>20 / 1$; Entry 1). Likewise, the glycosyl donor bearing SBiz moiety 7 readily underwent coupling with acceptor 2 , producing disaccharide 3 in $93 \%$ yield in 2 hours $(\alpha / \beta=11.2 / 1$; Entry 2). It was observed that glycosidation involving the acyclic SNea donor 8 took substantially longer (7 hours) but, nevertheless, disaccharide 3 was isolated in $92 \%$ yield $(\alpha / \beta=6.6 / 1$; Entry 3$)$. Pleased with the activation of the unreactive superdisarmed series, we turned our attention to glycosidations involving the per-benzoylated (disarmed) glycosyl donors. Thioimidate donors $9,{ }^{38} 12,{ }^{36}$ and $13^{35}$ underwent coupling smoothly and produced the expected 1,2-trans-linked disaccharides $10^{35}$ and $11^{35}$ in excellent yields (88\%-94\%; Entries 4-7). All reactions were relatively swift, and completed in 30-45 minutes. Disarmed thioglycoside $14^{45}$ reacted even more quickly (20 minutes) in the presence of $\mathrm{MeSBr}$ and $\mathrm{AgClO}_{4}(86 \%$ yield; Entry 8$)$.

We then began studying a series of per-benzylated (armed) glycosyl donors. Although all yields recorded were very commendable, the stereoselectivity observed was rather poor, most likely due to our inability to slow this reaction. Lowering the reaction temperature did not help, because it was favoring the formation of the kinetic ( $\beta$-linked) product. Thus, coupling of SBox donor $15^{38}$ with acceptor 2 produced disaccharide $16^{46}$ in $96 \%$ yield within 15 minutes $(\alpha / \beta=1.3 / 1$; Entry 9$)$. Similarly, donor 15 glycosidated with secondary glycosyl acceptor 5 to afford disaccharide $17^{46}$ in $89 \%$ yield in 15 minutes $(\alpha / \beta=1.6 / 1$; Entry 10$)$. Evaluation of per-benzylated thioimidoyl donors bearing the SBiz $18^{36}$ and SNea $19^{35}$ moieties was conducted, and their reactivity was found to be similar to that of the previously-mentioned glycosyl donors ( $89 \%$ and $91 \%$ yields; $\alpha / \beta=1.4 / 1$ and $1.3 / 1$; Entries 11 and 12, respectively). Thiophenyl donor $20^{47}$ also rapidly underwent coupling with $\mathrm{AgClO}_{4} / \mathrm{MeSBr}$, producing disaccharide 16 in $86 \%$ yield in 20 minutes $(\alpha / \beta=1.5 / 1$; Entry 13).

Glycosylations with SBox galactosyl (21), ${ }^{48}$ mannosyl (23), ${ }^{49}$ and 2-azido-2-deoxyglucosyl (25) donors were also conducted. It was observed that galactosyl and mannosyl glycosyl donors 21 and 23 underwent coupling with glycosyl acceptor 2 in the presence of $\mathrm{AgClO}_{4}$ in 15 minutes, with corresponding disaccharides $22^{50}$ and $24^{51}$ isolated in $83 \%$ and $87 \%$ yields, respectively. Unfortunately, no stereoselectivity was observed in these couplings $(\alpha / \beta=1 / 1.2$ and $1 / 1.1$; Entries 14 and 15). When we glycosidated 2-azido-2-deoxy donor 25 with acceptor 2 , disaccharide $26^{52}$ was produced in $89 \%$ yield $(\alpha / \beta=3.4 / 1)$. Finally, we investigated highly reactive (superarmed) glycosyl donors equipped with the 2-O-benzoyl-3,4,6-tri-O-benzyl protecting group pattern. ${ }^{48,53}$ All glycosidations of SBox (27), ${ }^{48} \mathrm{SBiz}(30),{ }^{36}$ and SNea $(31)^{35}$ donors with glycosyl acceptors 2 and 5 , in the presence of $\mathrm{AgClO}_{4}$, were exceptionally swift (less than 5 minutes). The respective disaccharides $28^{48}$ and $29^{48}$ were isolated in $82 \%-97 \%$ yields (Entries 17-20). A similar reaction rate was observed when SPh glycosyl donor $32^{54}$ was subjected to $\mathrm{AgClO}_{4} / \mathrm{MeSBr}$ activation conditions, affording disaccharide 28 in $82 \%$ yield (Entry 21 ). As anticipated, all glycosylations 


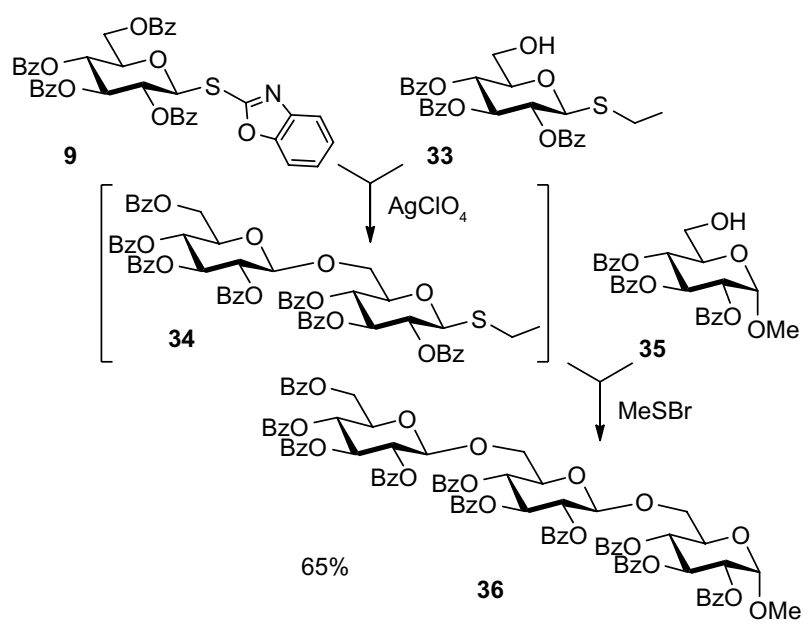

Figure 2 Synthesis of trisaccharide 36 via selective two-step activation in one pot.

with glycosyl donors of the superarmed series proceeded with complete $\beta$-selectivity.

Based on these results, it was also determined that a twostep, one-pot sequential activation, using building blocks with thioimidoyl and thioglycosyl leaving groups, was attainable by proper choice of promoter. The sequence envisioned was to first selectively activate thioimidoyl donor with thioglycoside acceptor in the presence of $\mathrm{AgClO}_{4}$. The expectation was that the resulting disaccharide could be activated directly, followed by addition of $\mathrm{MeSBr}$ and a new acceptor. To explore this possibility, SBox thioimidate donor 9 was coupled with thioglycosyl acceptor $33,{ }^{55}$ employing $\mathrm{AgClO}_{4}$ as the promoter (Figure 2). Upon disappearance of acceptor 33, as judged by TLC, the newly formed disaccharide 34 (not isolated) was then activated by the addition of $\mathrm{MeSBr}$ and glycosyl acceptor 35 . As a result, trisaccharide $36^{56}$ was obtained in $65 \%$ yield.

\section{Conclusion}

In conclusion, we demonstrated the effectiveness of silver (I) perchlorate as a powerful promoter towards glycosyl thioimidate activation. It has been utilized with a variety of donors of the gluco, galacto, manno, and glucosamino series. Also investigated was the use of $\mathrm{AgClO}_{4}$ as an additive, when paired with methyl sulfenyl bromide, to activate glycosyl thioglycosides. With superdisarmed glycosyl donors equipped with the 3,4,6-tri-O-benzoyl-2-O-benzyl protecting group pattern, $\mathrm{AgClO}_{4}$ was found to display improved 1,2-cis selectivity, in comparison to that obtained with other silver (I) salts, including commonly-used AgOTf. The sequential use of these activation protocols was applied to a one-pot, two-step synthesis of a trisaccharide, using thioimidate and thioglycoside building blocks.

\section{Acknowledgments}

This work was supported by an award from the US National Science Foundation (CHE-1058112). SJ Hasty is indebted to the University of Missouri-St Louis Graduate School, for providing him with the Dissertation Fellowship. Dr Winter and Mr Kramer (University of Missouri-St Louis) are thanked for their assistance with HRMS determinations.

\section{Disclosure}

The authors report no conflicts of interest in this work.

\section{References}

1. Varki A, Cummings RD, Esko JD, et al, editors. Essentials of Glycobiology. 2nd ed. Cold Spring Harbor, NY: Cold Spring Harbor Laboratory Press; 2009.

2. Demchenko AV. 1,2-cis O-Glycosylation: methods, strategies, principles. Curr Org Chem. 2003;7(1):35-79.

3. Demchenko AV. Stereoselective chemical 1,2-cis O-glycosylation: from "Sugar Ray" to modern techniques of the 21st century. Synlett. 2003;(9):1225-1240.

4. Crotti S, Adamo R. New strategies for the synthesis of bio-medically relevant oligosaccharides: Recent Updates on 1,2-cis-O-Glycosylation and $\alpha-O-$ Sialylation. Curr Org Synth. 2013;10:501-524.

5. Demchenko AV. General aspects of the glycosidic bond formation. In: Demchenko AV, editor. Handbook of chemical glycosylation. Weinheim, Germany: Wiley; 2008:1-27.

6. Ranade SC, Demchenko AV. Mechanism of chemical glycosylation: focus on the mode of activation and departure of anomeric leaving groups. J Carbohydr Chem. 2013;32:1-43.

7. Huang M, Garrett GE, Birlirakis N, Bohe L, Pratt DA, Crich D. Dissecting the mechanisms of a class of chemical glycosylation using primary ${ }^{13} \mathrm{C}$ kinetic isotope effects. Nature Chemistry. 2012;4: 663-667.

8. Mydock LK, Demchenko AV. Mechanism of chemical O-glycosylation: from early studies to recent discoveries. Org Biomol Chem. 2010;8: 497-510.

9. Crich D. Mechanism of a chemical glycosylation reaction. Acc Chem Res. 2010;43:1144-1153.

10. Zhu X, Schmidt RR. New principles for glycoside-bond formation. Angew Chem Int Ed. 2009;48:1900-1934.

11. Crich D. Chemistry of glycosyl triflates: Synthesis of $\beta$-mannopyranosides. J Carbohydr Chem. 2002;21(7-9):667-690.

12. Crich D, Sun S. Are glycosyl triflates intermediates in the sulfoxide glycosylation method? A chemical and ${ }^{1} \mathrm{H},{ }^{13} \mathrm{C}$, and ${ }^{19} \mathrm{~F}$ NMR spectroscopic investigation. J Am Chem Soc. 1997;119(46): 11217-11223.

13. Lemieux RU, Hendriks KB, Stick RV, James K. Halide ion catalyzed glycosylation reactions. Syntheses of $\alpha$-linked disaccharides. J Am Chem Soc. 1975;97(14):4056-4062.

14. Gervay J, Hadd MJ. Anionic additions to glycosyl iodides: highly stereoselective syntheses of $\beta-\mathrm{C}-$, N-, and O-glycosides. J Org Chem. 1997;62:6961-6967.

15. Gervay J, Nguyen TN, Hadd MJ. Mechanistic studies on the stereoselective formation of glycosyl iodides: first characterization of glycosyl iodides. Carbohydr Res. 1997;300(2):119-125.

16. Kochetkov NK, Klimov EM, Malysheva NN, Demchenko AV. A novel highly stereospecific method of 1,2-cis-glycosylation - synthesis of $\alpha$-D-glucosyl-D-hexoses and $\alpha$-D-galactosyl-D-hexoses. Bioorg Khim. 1990;16(5):701-710.

17. Kochetkov NK, Klimov EM, Malysheva NN. Novel highly stereospecific method of 1,2-cis-glycosylation. Synthesis of $\alpha$-D-glucosyl-D-glucoses. Tetrahedron Lett. 1989;30(40):5459-5462. 
18. Kaeothip S, Akins SJ, Demchenko AV. On the stereoselectivity of glycosidation of thiocyanates, thioglycosides, and thioimidates. Carbohydr Res. 2010;345:2146-2150.

19. Veeneman GH, van Boom JH. An efficient thioglycoside-mediated formation of alpha-glycosidic linkages promoted by iodonium dicollidine perchlorate. Tetrahedron Lett. 1990;31(2):275-278.

20. Demchenko A, Stauch T, Boons GJ. Solvent and other effects on the stereoselectivity of thioglycoside glycosidations. Synlett. 1997;(7):818-820.

21. Mukaiyama T, Matsubara K. Stereoselective glycosylation reaction starting from 1-O-trimethylsilyl sugars by using diphenyltin sulfide and a catalytic amount of active acidic species. Chem Lett. 1992;1992(6):1041-1044.

22. Adinolfi M, Barone G, Guariniello L, Iadonisi A. Efficient activation of armed glycosyl trichloroacetimidates with $\mathrm{Sm}(\mathrm{OTf})_{3}$ in the stereoselective glycosidation of saccharidic acceptors. Tetrahedron Lett. 2000;41(46):9005-9008

23. Schene H, Waldmann H. Activation of glycosyl phosphites under neutral conditions in solutions of metal perchlorates in organic solvents. Eur J Org Chem. 1998:1227-1230.

24. Fukase K, Hasuoka A, Kinoshita I, Aoki Y, Kusumoto S. A stereoselective glycosidation using thioglycosides, activation by combination of N-bromosuccinimide and strong acid salts. Tetrahedron 1995;51(17):4923-4932.

25. Worm-Leonhard K, Larsen K, Jensen KJ. 4,6-O-benzylidene directed b-mannosylation without intermediate triflate formation? Comparison of trichloroacetimidate and DISAL donors in microwavepromoted glycosylations under neutral conditions. J Carbohydr Chem. 2007;26:349-368.

26. Dalpozzo R, Bartoli G, Sambri L, Melchiorre P. Perchloric acid and its salts: very powerful catalysts in organic chemistry. Chem Rev. 2010;110:3501-3551.

27. Igarashi K, Honma T, Irisawa J. Reaction of glycosyl chlorides with silver perchlorate. Carbohydr Res. 1970;15:329-337.

28. Mukaiyama T, Murai Y, Shoda S-i. An efficient method for glucosylation of hydroxy compounds using glucopyranosyl fluoride. Chem Lett. 1981(3):431-432.

29. Demchenko AV, Kamat MN, De Meo C. S-Benzoxazolyl (SBox) glycosides in oligosaccharide synthesis: novel glycosylation approach to the synthesis of $\beta$-D-glucosides, $\beta$-D-galactosides, and $\alpha$-D-mannosides. Synlett. 2003:1287-1290.

30. Kochetkov NK, Klimov EM, Malysheva NN, Demchenko AV. Stereospecific synthesis of 1,2-cis-glycosides of 2-amino sugars. Carbohydr Res. 1993;242:C7-C10.

31. Dasgupta F, Garegg PJ. Use of sulfonyl halides in carbohydrate reactions. Part I. Alkyl sulfonyl triflate as activator in the thioglycoside-mediated formation of beta-glycosidic linkages during oligosaccharide synthesis. Carbohydr. Res. 1988;177:C13-C17.

32. Hasty SJ, Demchenko AV. Glycosyl thioimidates as versatile building blocks for organic synthesis. Chem Heterocycl Compd. 2012;48:220-240.

33. Demchenko AV, Malysheva NN, De Meo C. S-Benzoxazolyl (SBox) glycosides as novel, versatile glycosyl donors for stereoselective 1,2-cis glycosylation. Org Lett. 2003;5:455-458.

34. Demchenko AV, Pornsuriyasak P, De Meo C, Malysheva NN. Potent, versatile, and stable: thiazolyl thioglycosides as glycosyl donors. Angew Chem Int Ed. 2004;43:3069-3072.

35. Ranade SC, Kaeothip S, Demchenko AV. Glycosyl alkoxythioimidates as complementary building blocks for chemical glycosylation. Org Lett. 2010;12:5628-5631.

36. Hasty SJ, Kleine MA, Demchenko AV. S-Benzimidazolyl glycosides as a platform for oligosaccharide synthesis by an active-latent strategy Angew Chem Int Ed. 2011;50:4197-4201.
37. Kaeothip S, Pornsuriyasak P, Demchenko AV. Silver(I) tetrafluoroborate as a potent promoter for chemical glycosylation. Tetrahedron Lett. 2008;49:1542-1545.

38. Kamat MN, Demchenko AV. Revisiting the armed-disarmed concept rationale: chemoselective activation of the S-benzoxazolyl glycosides in oligosaccharide synthesis. Org Lett. 2005;7:3215-3218.

39. Kamkhachorn T, Parameswar AR, Demchenko AV. Comparison of the armed/disarmed building blocks of the D-gluco and D-glucosamino series in the context of chemoselective oligosaccharide synthesis. Org Lett. 2010;12:3078-3081.

40. Crich D. Methodology development and physical organic chemistry: A powerful combination for the advancement of glycochemistry. J Org Chem. 2011;76:9193-9209.

41. Kamat MN, Rath NP, Demchenko AV. Versatile synthesis and mechanism of activation of S-benzoxazolyl glycosides. J Org Chem. 2007;72:6938-6946.

42. Zhong W, Boons G-J. Glycoside synthesis from 1-sulfur/seleniumsubstituted derivatives: thioglycosides in oligosaccharide synthesis. In: Demchenko AV, editor. Handbook of Chemical Glycosylation. Weinheim, Germany: Wiley; 2008:261-303.

43. Premathilake HD, Demchenko AV. Superarmed and superdisarmed building blocks in expeditious oligosaccharide synthesis. In: FraserReid B, Lopez JC, editors. Topics in Current Chemistry: Reactivity Tuning in Oligosaccharide Assembly. Berlin-Heidelberg: Springer-Verlag; 2011;301:89-221.

44. Kaeothip S, Yasomanee JP, Demchenko AV. Glycosidation of thioglycosides in the presence of bromine: mechanism, reactivity, and stereoselectivity. J Org Chem. 2012;77:291-299.

45. Ferrier RJ, Furneaux RH. Synthesis of 1,2-trans-related 1-thioglycoside esters. Carbohydr Res. 1976;52:63-68.

46. Garcia BA, Gin DY. Dehydrative glycosylation with activated diphenyl sulfonium reagents. Scope, mode of C(1)-hemiacetal activation, and detection of reactive glycosyl intermediates. $\mathrm{J} \mathrm{Am}$ Chem Soc. 2000;122:4269-4279.

47. Pfaeffli PJ, Hixson SH, Anderson L. Thioglycosides having O-benzyl blocking groups as intermediates for the systematic, sequential synthesis of oligosaccharides. Synthesis of isomaltose. Carbohydr Res. 1972;23:195-206.

48. Mydock LK, Demchenko AV. Superarming the S-benzoxazolyl glycosyl donors by simple 2-O-benzoyl-3,4,6-tri-O-benzyl protection. Org Lett. 2008;10:2103-2106.

49. De Meo C, Kamat MN, Demchenko AV. Remote participation-assisted synthesis of b-mannosides. Eur J Org Chem. 2005:706-711.

50. Nokami T, Shibuya A, Tsuyama H, et al. Electrochemical generation of glycosyl triflate pools. J Am Chem Soc. 2007;129:10922-10928.

51. Hotha S, Kashyap S. Propargyl glycosides as stable glycosyl donors: anomeric activation and glycosyl syntheses. J Am Chem Soc. 2006;128:9620-9621.

52. Tsuda T, Nakamura S, Hashimoto S. A highly stereoselective construction of 1,2-trans- $\beta$-glycosidic linkages capitalizing on 2-azido-2-deoxy-D-glycosyl diphenyl phosphates as glycosyl donors. Tetrahedron. 2004;60:10711-10737.

53. Premathilake HD, Mydock LK, Demchenko AV. Superarming common glycosyl donors by simple 2-O-benzoyl-3,4,6-tri-O-benzyl protection. J Org Chem. 2010;75:1095-1100.

54. Nicolaou KC, Mitchell HJ, Jain NF, et al. Total synthesis of vancomycinPart 4: Attachment of the sugar moieties and completion of the synthesis. Chem Eur J. 1999;5:2648-2667.

55. Agoston K, Kroeger L, Dekany G, Thiem J. On resin modification of monosaccharides. J Carbohydr Chem. 2007;26:513-525.

56. Ranade SC, Hasty SJ, Demchenko AV. Comparative study of glycosyl thioimidates as building blocks for chemical glycosylation. J Carbohydr Chem. 2013;32:360-379. 
Reports in Organic Chemistry

Dovepress

\section{Publish your work in this journal}

Reports in Organic Chemistry is an international, peer-reviewed, open access journal publishing original research, reports,

Visit http://www.dovepress.com/testimonials.php to read real quotes reviews and commentaries on all areas of organic chemistry. The manuscript management system is completely online and includes a very quick and fair peer-review system, which is all easy to use. from published authors.

Submit your manuscript here: http://www.dovepress.com/reports-in-organic-chemistry-journal 